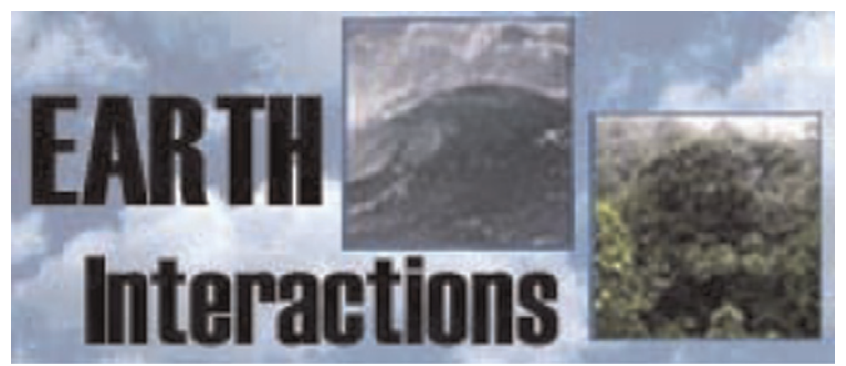

Copyright (C 2011, Paper 15-019; 4477 words, 2 Figures, 0 Animations, 1 Tables. http://EarthInteractions.org

\title{
Bootstrapping Wildfire Selectivity for the Forest Types of Canton Ticino (Switzerland)
}

\section{Sofia Bajocco*}

Unit of Climatology and Meteorology Applied to Agriculture, Council for Research in Agriculture (CRA-CMA), and Department of Plant Biology, Sapienza University of Rome, Rome, Italy

\section{Gianni Boris Pezzatti}

Insubric Ecosystems Research Group, WSL Swiss Federal Research Institute, Bellinzona, Switzerland

\section{Antonella De Angelis}

Department of Plant Biology, Sapienza University of Rome, Rome, Italy

\section{Marco Conedera}

Insubric Ecosystems Research Group, WSL Swiss Federal Research Institute, Bellinzona, Switzerland

\section{Carlo Ricotta}

Department of Plant Biology, Sapienza University of Rome, Rome, Italy

Received 13 October 2010; accepted 30 January 2011

* Corresponding author address: Sofia Bajocco, Unit of Climatology and Meteorology Applied to Agriculture, Council for Research in Agriculture (CRA-CMA), Via del Caravita 7a, 00186 Rome, Italy.

E-mail address: sofia.bajocco@entecra.it 
Earth Interactions - Volume 15 (2011) • Paper No. 19 • Page 2

\begin{abstract}
Disturbances spreading through the landscape, like wildfires, are essential processes in modeling landscape structure and dynamics. Like other disturbances, fire may spread from a local epicenter with a propagation rate enhanced or retarded by the spatial arrangement of fuel across the landscape. Therefore, fire ignition and spread are a direct consequence of the presence and arrangement of fire-prone habitats. Generalizing the concept of "habitat selection" to every spatially distributed ecological process, the resource selection functions used in zoology to summarize habitat use by wildlife can be also used to characterize the wildfire's pattern across the landscape. The aim of this paper is thus to quantify the relationship between forest cover and burnt area in Canton Ticino (Switzerland) during 1980-2007 using a bootstrap test of significance: that is, to identify forest types that burn more (or less) than expected from a random null model based on the regional availability of the resource (forest type). The results show that fires behave selectively for most forest types; whereas chestnut stands and broad-leaved forests display overproportional burnt areas, coniferous forests typically burn less than expected by a random null model.
\end{abstract}

KEYWORDS: Burnt area; Canton Ticino (Switzerland); Fire spread; Permutation methods; Forest types

\title{
1. Introduction
}

Fires ignite and spread across the landscape as a function of the presence and spatial arrangement of the fuel load associated to the different land-cover types. Accordingly, to understand fire behavior at the regional scale, a key question consists in quantifying the spatial patterns of fire selectivity regarding landscape composition (Moreira et al. 2001).

Analysis of habitat selection is a common aspect of wildlife science because the comprehension of how wildlife use habitat is of great importance to ecology and management of any species (McClean et al. 1998). In zoology, this kind of study uses the resource selection functions (RSFs), which are statistical models defined to be proportional to the probability of use of a given resource type (Manly et al. 2002; Boyce 2006). A wide variety of RSFs have been used to analyze the habitat selection by animals, such as habitat preference analysis (Johnson 1980), compositional analysis (Aebischer et al. 1993), log-linear models (Heisey 1985), logistic regressions (Pereira and Itami 1991), or multiresponse permutation procedures (MRPP; Mielke 1986; Alldredge et al. 1998). For a thorough review on RSFs, see Manly et al. (Manly et al. 2002). The aim is to go beyond simple documentation of habitat use and to determine if specific habitats are positively or negatively selected, that is, used more or less than availability (Alldredge and Ratti 1986).

Generalizing the concept of habitat selection to every spatially distributed ecological process, the RSFs can be also used to characterize the distribution of wildfires across the landscape (Manly et al. 2002; Nielsen et al. 2005). In this view, according to Moreira et al. (Moreira et al. 2001), fire can be considered as an "herbivore" that exhibits variable preferences for different types of vegetation or land-cover classes. If fires ignite and spread unselectively over the landscape, then the land-cover composition (the proportional area of various land-cover types) burned by fires should approximate the land-cover composition available in the 
Earth Interactions - Volume 15 (2011) • Paper No. 19 • Page 3

entire region (Nunes et al. 2005). In this paper, we used a bootstrap test of significance for analyzing the selectivity of forest fires in terms of total burnt area (as the result of fire ignition and spread) in an intermediate fire-prone region such as the Swiss Canton of Ticino during 1980-2007.

\section{Material and methods}

\subsection{Study area}

Canton Ticino is a 2812- $\mathrm{km}^{2}$ region located on the southern slope of the Alps in the Italian-speaking part of Switzerland (Figure 1). The area is characterized by a marked altitudinal gradient, ranging from 197 m MSL around Lake Maggiore (Locarno) to $3402 \mathrm{~m}$ on the Adula Peak in northern Ticino. The geology of the area is dominated by siliceous rock with small spots of limestone, except in the very southern part, where only limestone is present.

The area is generally characterized by a warm temperate and rainy climate, although the precipitation is often concentrated in short and heavy spells, and there can be longer periods without rain or even drought. The mean annual precipitation ranges from 1600 to $2600 \mathrm{~mm}$, and the mean annual temperature ranges from $3^{\circ}$ to $12^{\circ} \mathrm{C}$, depending on the elevation and the geographic position. The precipitation in the main vegetation period (June-September) ranges from 800 to $1200 \mathrm{~mm}$. The

duration of sunshine is high (1800-2150 $\left.\mathrm{h} \mathrm{yr}^{-1}\right)$, although some valleys during winter may be shaded by the surrounding mountains for several weeks. Winds are usually weak, but strong gusts may occur during thunderstorms and when there is a katabatic (descending) dry wind from the north (föhn) for up to 40 days a year on average. One of the main consequences of the föhn is a drop in the relative air humidity to values as low as $20 \%$ and the quick drying off of the fine fuel.

At low elevations (from 200 up to $900-1100 \mathrm{~m}$ MSL) forest vegetation is dominated by chestnuts (Castanea sativa), which was first cultivated (and probably first introduced) in the area by the Romans. Chestnut forests are anthropogenic monocultures occasionally interrupted by the presence of other broad-leaved species, such as Tilia cordata, Quercus petraea, Q. pubescens, Alnus glutinosa, Prunus avium, Acer spp., or Fraxinus spp. At medium elevations (900-1400 m MSL), the forests mostly consist of pure stands of Fagus sylvatica, followed by coniferous forests (Picea abies and, at higher elevations, Larix decidua). On the south-facing slopes, the beech belt is sometimes completely missing. The presence of Abies alba has been reduced to small patches on north-facing slopes in the central part of the area, whereas pine forests are confined to very particular sites (Pinus sylvestris on dry south-facing slopes and P. cembrae on the most continental areas of the upper regions).

\subsection{Forest-cover map}

Because no reliable forest vegetation map of the study area exists, we used thematic forest maps of different origin, content, and levels of precision and combined them using the hierarchical approach proposed by Pezzatti et al. (2009) to determine the forest vegetation cover on a $25 \mathrm{~m} \times 25 \mathrm{~m}$ grid. 


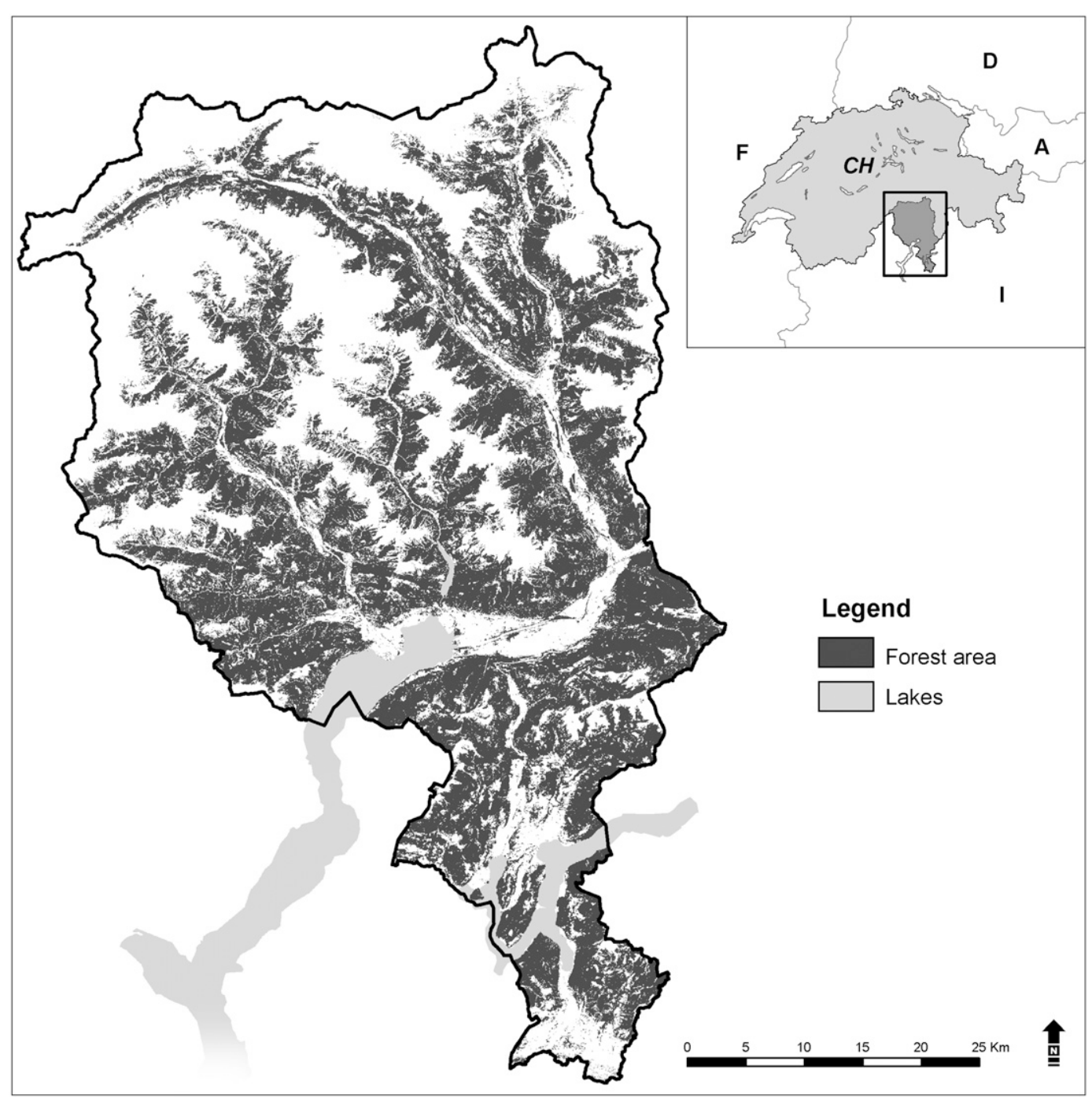

Figure 1. Location of the study area (Canton Ticino).

Overall, nine forest-cover classes were defined, covering 127903 ha (i.e., roughly $45.5 \%$ of the study area). To account for forest fires originating outside the forest area or trespassing forest gaps, we considered two additional forest-cover types, which consisted of two buffer zones $(0-50 \mathrm{~m}$ and $50-100 \mathrm{~m})$ starting from the forest edge. The 11 land-cover classes and their extent in the study area are shown in Table 1.

\subsection{Forest fire data}

In Canton Ticino, forest fires are recorded by the Cantonal Forest Service. The information includes date and time of ignition; duration; ignition cause; burnt area; 
Earth Interactions - Volume 15 (2011) • Paper No. 19 • Page 5

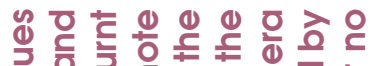
흥응

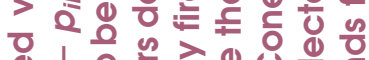
ब 1 응

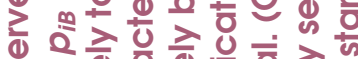

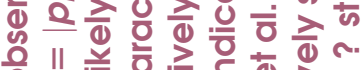
is is o 政 ه

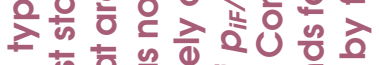

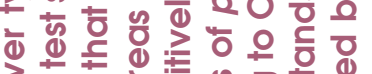
응

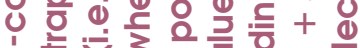
क् क

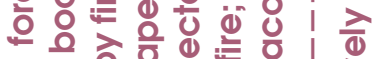

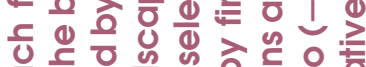

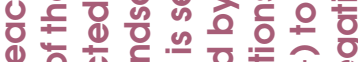

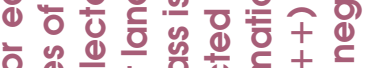
훙 $\frac{1}{0}$ 흔

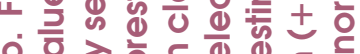

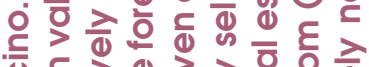

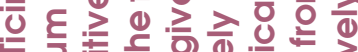

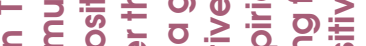
ᄃ

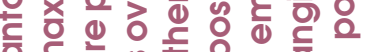

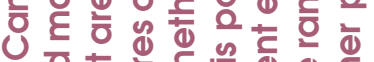

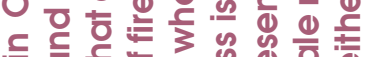

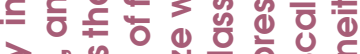
خี

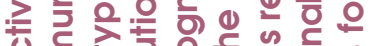

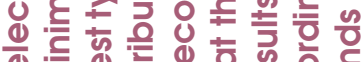

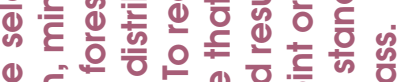

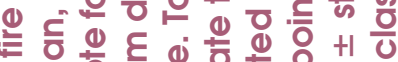

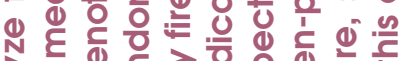

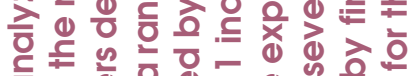

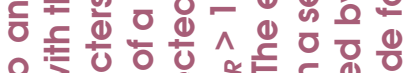
우 3 은

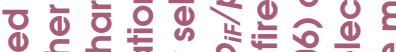

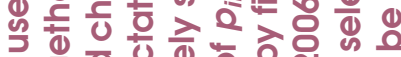

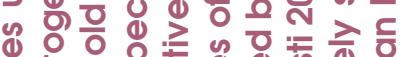

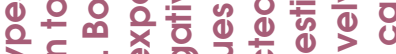

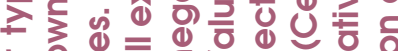
过 0 잉워

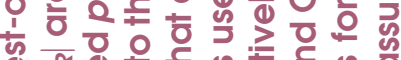

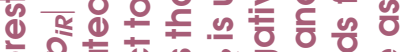
후은 웡 140 - 20

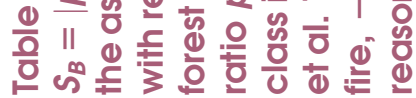

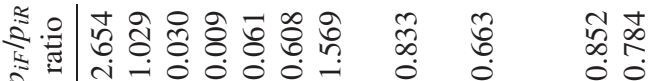

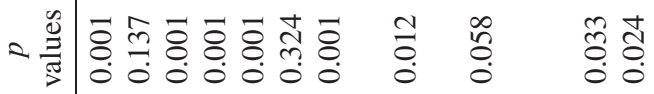

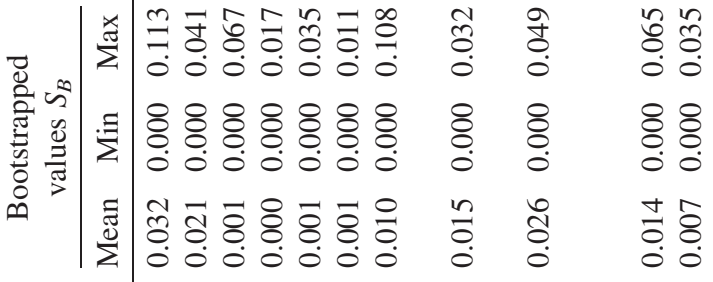

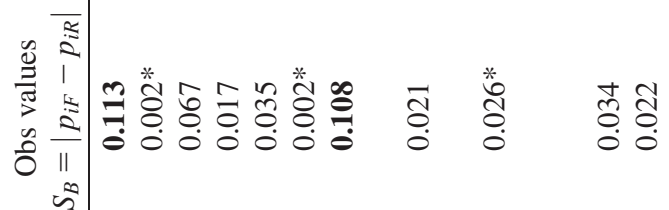

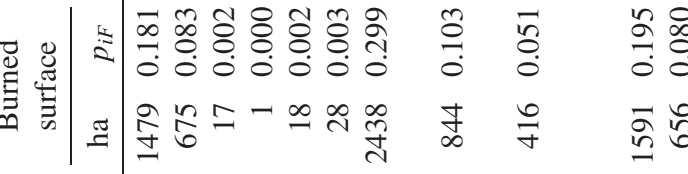

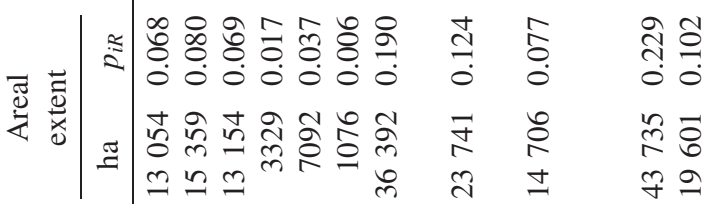

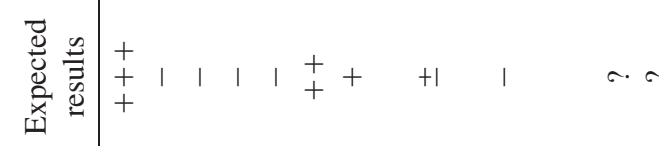

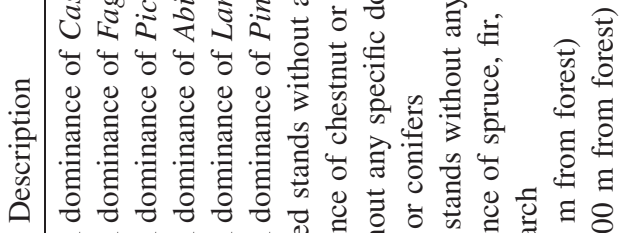

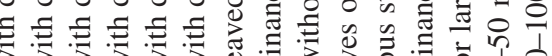

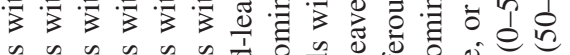

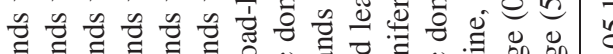

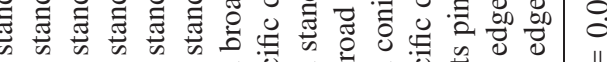

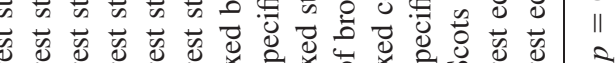

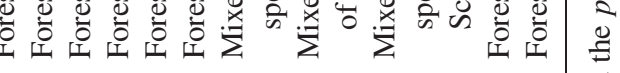

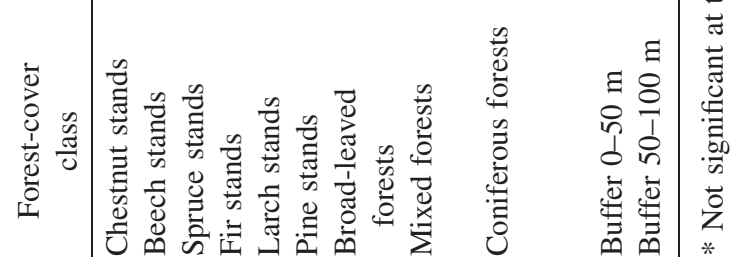


Earth Interactions - Volume 15 (2011) • Paper No. 19 • Page 6

fire type; forest type; and, for most fires since 1969, a georeferenced perimeter of the burnt area. All data are checked for quality and entered in the Forest Fire Database (Pezzatti et al. 2005). According to fire statistics, a mixed fire regime exists in the study area: anthropogenic fires during the winter season (December through April) and anthropogenic and natural fires during the summer season (May through November). Because of changes in the fire fighting organization and tactics, homogeneous burning conditions in terms of fire spread and control have only existed since 1980, when the fire brigade coordination passed from the single communities to the Canton and aerial fire fighting with helicopters started in a systematic way (Conedera et al. 2004). Since then, fire extinction actions are generally very efficient and, during the main winter fire season, most of the forest fires $(90 \%)$ do not burnt more than 10 ha. In particular cases (i.e., dry and windy conditions during the fire season), multiple ignitions and an elevated rate of spread may overburden the capacity of the fire fighting organization and result in an intense and extended fire, as was the case in 1990 and 1997.

To have a homogeneous dataset, we consider for the present study only the winter fires for the period 1980-2007. According to this selection criterion, a total of 894 events with a georeferenced perimeter of the burnt area were considered. The annual number of fires varies mostly according to the weather conditions (Figure 2).

To calculate the burned area within each forest-cover class, first the georeferenced burned areas of each fire were overlaid on the forest-cover map. In this way, we obtained 11 dimensional forest-cover compositional vectors for each fire. The recorded size of burned forest-cover ranges between 1 and 2695 pixels; the total forest surface burned by those winter fires during 1980-2007 is 130609 pixels (roughly corresponding to $8163 \mathrm{ha}$ ). Then, a vector of burned forest-cover composition for the whole study area was obtained simply as the sum of the single-fire compositional vectors.

\subsection{Analysis}

We tested the significance of fire selectivity of the mapped forest-cover classes with bootstrap methods (Efron 1979). The bootstrap can be applied in situations where standard statistical tools do not exist or where the usual statistical methods are inappropriate because the underlying assumptions (e.g., normality, constant variance, etc.) are violated. The essence of bootstrapping is the idea that, in the absence of any other piece of information about a population, the distribution of values found in a random sample of given size from the population is the best guide to the distribution in the population. Therefore, to approximate what would happen if the population was resampled, a reasonable approach consists in resampling the sample. The sampling is with replacement, which is the only difference in practice between bootstrapping and ordinary randomization in many applications (Manly 2007).

Given a test statistic $S$, a bootstrap test consists in comparing the value of $S$ for the available data with the bootstrap distribution of $S$. If the actual value of $S$ is sufficiently extreme in comparison to the bootstrap distribution, the null hypothesis is rejected. Dealing with fire selectivity, our aim is to test whether the proportional 


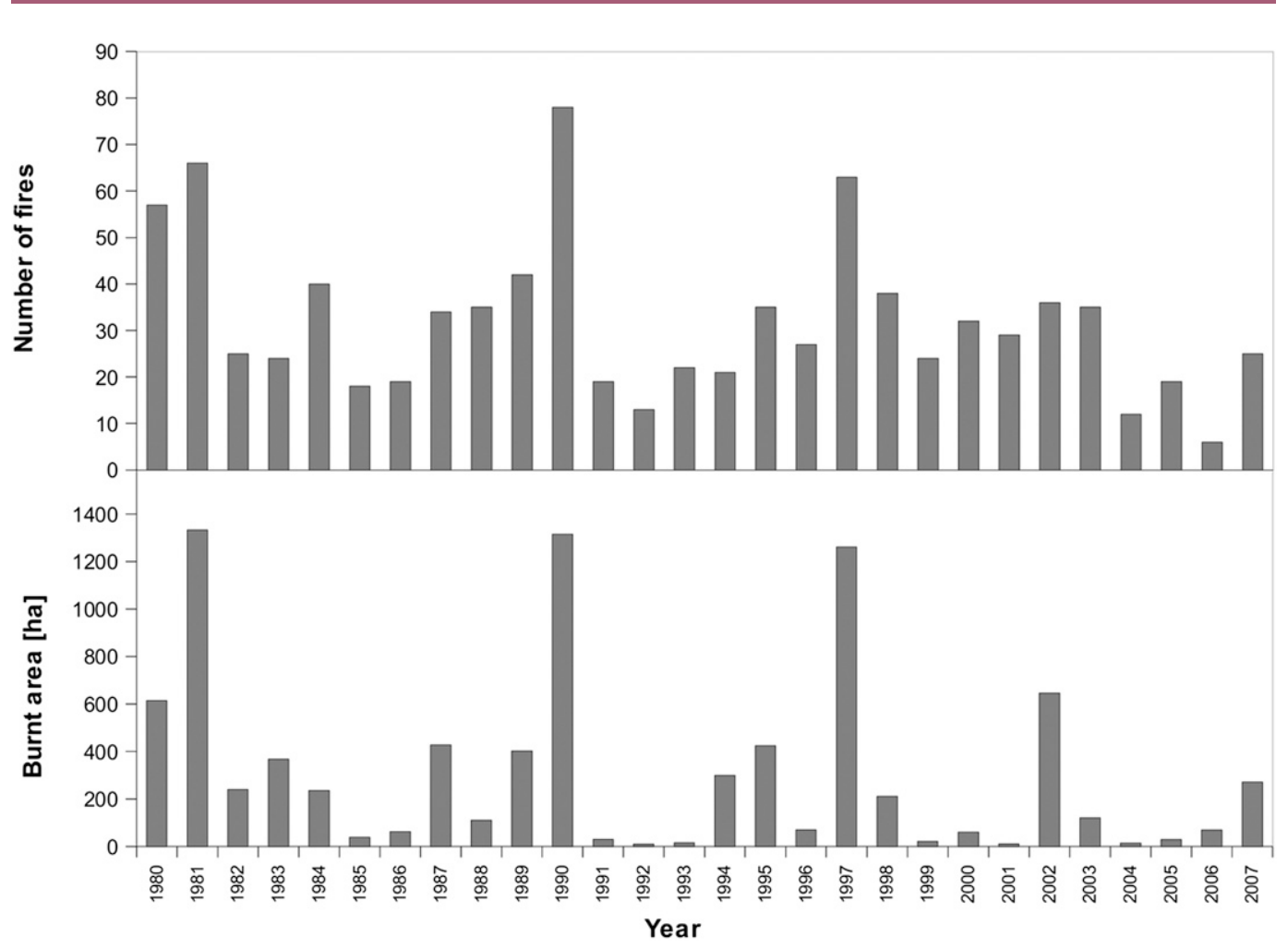

Figure 2. Annual number and burnt area of winter fires (November-April) with georeferenced perimeter in Canton Ticino (1980-2007).

area of a given forest-cover type $i$ burned by fires $p_{i F}$ is significantly different from the proportional area of that cover type in the entire region $p_{i R}$. As fire selectivity can be either positive or negative (i.e., a given forest type can burn either more or less than expected from a random null model), a two-sided test is needed.

In principle, an appropriate bootstrap test statistic might be $S_{B}=\left|p_{i B}-p_{i R}\right|$, where $p_{i B}$ is the bootstrapped proportional area of a given forest type burned by fires that is obtained by resampling with replacement of the 11 dimensional compositional vectors of single fires. However, as shown by Manly (Manly 2007), $S_{B}$ is not an adequate test statistic. This is because, if $\left|p_{i F}-p_{i R}\right|$ is large, then all values of $S_{B}$ tend to be large as well. Then, "the bootstrap distribution will in this case reflect the distribution of the statistic when the null hypothesis is not true, rather than the distribution when the null hypothesis is true" (Manly 2007). Therefore, the data need to be adjusted to reflect the distribution of the statistic when the null hypothesis is true. A straightforward method consists in comparing instead $\left|p_{i F}-p_{i R}\right|$ with the bootstrap distribution of $S_{B}^{\prime}=\left|p_{i B}-p_{i F}\right|$. According to Manly (Manly 2007), this is equal to using the distribution of absolute differences between the bootstrapped proportional areas burned and the actual proportional areas burned to mimic the distribution of the differences between the original sample statistics and the population statistics.

A test of significance of fire selectivity for the 11 forest-cover classes used in this study was performed using 999 bootstrap samples. After identifying a forest-cover 
class for which the null hypothesis is rejected, the ratio $p_{i F} / p_{i R}$ is used to recognize whether the class is selected positively or negatively by fire. Values of $p_{i F} / p_{i R}>1$ indicate that the class burns disproportionately more than expected from a random null model; by contrast, if $p_{i F} / p_{i R}<1$, the class is negatively selected by fire. The results obtained were confronted with the empirical results of Conedera et al. (Conedera et al. 1996) and Cesti (Cesti 2006) based on the fire statistics and field observations on the analyzed forest-cover classes.

\section{Results}

According to the bootstrap test of significance, in Canton Ticino most forest types burn disproportionately to their regional availability (Table 1). In chestnut stands and broad-leaved forests $p_{i F} / p_{i R}>1$ (with $p$ values $=0.001$ ), meaning that the burnt surface is significantly higher than expected from a random null model. To the contrary, spruce, fir, and larch stands are negatively selected in terms of burnt area by fire with $p_{i F} / p_{i R}<1$ and $p$ values $<0.05$, whereas mixed forests and the two buffer zones outside the forest edge $(0-50 \mathrm{~m}$ and $50-100 \mathrm{~m})$ show a marginal negative fire selectivity $\left(p_{i F} / p_{i R}<1 ; p<0.1\right)$. Finally, beech and pine stands burn in proportion to their availability without any significant tendency toward fire preference or avoidance.

\section{Discussion}

A number of studies dealt with the selectivity of fire with respect to land-cover classes and vegetation types. Most of them managed to statistically analyze the selectivity of the different vegetation types to wildfire ignitions (Vasconcelos et al. 2001; Bajocco and Ricotta 2008; Catry et al. 2009; Pezzatti et al. 2009). Much more difficult is the analysis of the fire selectivity in terms of total burnt area as the result of fire ignition and successive spread (Cumming 2001; Nunes et al. 2005; Podur and Martell 2009). In this study, we used a bootstrap approach to test forest fire selectivity in terms of burnt area in Canton of Ticino during the period 19802007.

According to Conedera et al. (Conedera et al. 1996), taking into account the pyrological fuel characteristic and the geographic distribution of the different forest types, the most fire-prone forest type in the study area during winter is the chestnut stand. Chestnut stands are very prone to anthropogenic fire ignition because of their vicinity to human activities (Pezzatti et al. 2009) and display an abundant and very light packed litter layer that enhances fast-spreading surface fires. Although not very distant to roads and urban settlements, site slopes are high enough $\left(25^{\circ}-30^{\circ}\right)$ to make terrestrial fire fighting difficult. To the contrary, pure beech stands are generally distant to the main settlement area and produce a compact and less aerobic litter layer that tends to slow down the fire spread, reducing the general extent of burnt areas in this forest type. The discrepancy between expected and obtained results in beech forests may be due to a few large fires that hit this type of stand in the last decade. Although beech forests are usually considered resistant to fire spread, in the case of extreme dry climatic condition in spring, the fuel load in beech forests may become prone to fast-spreading surface 
Earth Interactions - Volume 15 (2011) - Paper No. 19 • Page 9

fires. The other broad-leaved forests, especially when rich in oaks, may display similar spreading patterns and fire fighting difficulties as the chestnut stand, even if to a lesser extent (Cesti 2006). Spruce and larch stands and other coniferous trees usually display fuel characteristic, such as the compact and anaerobic needle layer and a high altitudinal distribution that safeguard them from fast-spreading winter fires. The dominant north-facing aspect of the fir stand sites may even increase this effect. In contrast, pine stands are mostly represented on south-facing slopes by Pinus sylvestris stands. Although these pine stands are easily accessible by the fire fighting brigades because of their proximity to roads and settlements, they may cause rapid-spreading surface to crown fires (Cesti 2006). Mixed forests may behave very heterogeneously according to their location (anthropogenic fire ignition) and the percentage and the type of broad-leaved and coniferous species, respectively (fire spread). The two buffer zones represent very heterogeneous categories in terms of both fuel type and geographic distribution, such that no theoretical assumption can be made concerning their selectivity with respect to the burnt area; nonetheless, bootstrap analysis indicates a negative selectivity of such buffer areas, probably because of the generally low fuel load.

Comparing such empirical observations with the results of the proposed test of significance, we note that bootstrapping adequately fits our expectations on the selectivity of broad-leaved forests and chestnut and spruce stands while providing significant results even for the buffer zones. In particular, the bootstrap approach provides significant results also for the less abundant forest categories, such as fir and larch stands. It fails, however, to confirm the expected fire behavior in beech and pine stands as well as in mixed coniferous forests. Concerning the pine stands, in the study area most of them are patches of reduced extension growing on rocky south-facing slopes where the discontinuity in the fuel on the soil may cause a much greater reduction in the fire-spread danger as assumed from a theoretical viewpoint. For the mixed coniferous forests, the reason for the lack of results in the bootstrapping approach may lie in the particular condition and typology of the stands affected by fire in wintertime. In fact, at low elevations, most coniferous forest stands actually consist of tree plantations in which fire spread is usually higher than in natural coniferous stands. Accordingly, the total burnt area within the coniferous forest type is obtained from the sum of fires in both natural and planted coniferous stands, giving rise to contradictory results.

Forest selectivity with respect to the total burnt area is best analyzed when complete information on the fire perimeter and related fuel maps are available. In the ideal case, fuel maps should contain quantitative characterizations of fuel types based on stand structure and composition, surface and ladder fuels, and forest floor cover (Nunes et al. 2005; Nadeau and Englefield 2006). However, because fuel type characterization on coarse spatial scales is a very complex operation (Keane et al. 2001; Lasaponara and Lanorte 2007), a number of studies (e.g., Nunes et al. 2005; Bajocco and Ricotta 2008; Pezzatti et al. 2009) used land-cover classes as a surrogate for fuel types. In this framework, given the relative homogeneity in the amount and spatial continuity of fuel load within each class, the 11 forest-cover classes used in this study may be considered adequate to investigate fire incidence patterns on the landscape scale. In addition, the distribution of the different forest types along the altitudinal or geological gradient may result in different vegetation belts or units representing also different ecological and geophysical 
Earth Interactions • Volume 15 (2011) • Paper No. 19 • Page 10

conditions that may influence both fire ignition and spread and thus the resulting total burnt area.

Acknowledgments. This study has been supported by the European Commission under the 6th Framework Programme through the integrated project "An Innovative Approach of Integrated Wildland Fire Management Regulating the Wildfire Problem by the Wise Use of Fire: Solving the Fire Paradox," Contract FP6-018505 (FIRE PARADOX).

\section{References}

Aebischer, N. J., P. A. Robertson, and R. E. Kenward, 1993: Compositional analysis of habitat use from animal radio-tracking data. Ecology, 74, 1313-1325.

Alldredge, J. R., and J. T. Ratti, 1986: Comparison of some statistical techniques for analysis of resource selection. J. Wildl. Manage., 50, 157-165.

— D. L. Thomas, and L. L. McDonald, 1998: Survey and comparison of methods for study of resource selection. J. Agric. Biol. Environ. Stat., 3, 237-253.

Bajocco, S., and C. Ricotta, 2008: Evidence of selective burning in Sardinia (Italy): Which land cover classes do wildfires prefer? Landscape Ecol., 23, 241-248.

Boyce, M. S., 2006: Scale for resource selection functions. Diversity Distrib., 12, 269-276.

Catry, F. X., F. C. Rego, F. L. Bação, and F. Moreira, 2009: Modelling and mapping the occurrence of wildfire ignitions in Portugal. Int. J. Wildland Fire, 18, 921-931.

Cesti, G., 2006: I combustibili negli incendi di vegetazione. Collana di monografie sugli incendi boschivi e di vegetazione, Aosta, IT, $202 \mathrm{pp}$.

Conedera, M., and Coauthors, 1996: Incendi boschivi al Sud delle Alpi: passato, presente e possibili sviluppi futuri. Rapporto di lavoro del Programma Nazionale di Ricerca "Mutamenti climatici e catastrofi naturali'" PNR 3, 143 pp.

—, G. Corti, P. Piccini, D. Ryser, F. Guerini, and I. Ceschi, 2004: La gestione degli incendi boschivi in Canton Ticino: Tentativo di una sintesi storica. Schweiz. Z. Forstwes., 155, 263-277.

Cumming, S. G., 2001: Forest type and wildfire in the Alberta boreal mixed wood: What do fires burn? Ecol. Appl., 11, 97-110.

Efron, B., 1979: Bootstrap methods: Another look at the jackknife. Ann. Stat., 7, 1-26.

Heisey, D. M., 1985: Analyzing selection experiments with log-linear models. Ecology, 66, 17441748.

Johnson, D. H., 1980: The comparison of usage and availability measurements for evaluating resource preference. Ecology, 61, 65-71.

Keane, R. E., R. Burgan, and J. Van Wagtendonk, 2001: Mapping wildland fuels for fire management across multiple scales: Integrating remote sensing, GIS, and biophysical modelling. Int. J. Wildland Fire, 10, 301-319.

Lasaponara, R., and A. Lanorte, 2007: On the capability of satellite VHR QuickBird data for fuel type characterization in fragmented landscapes. Ecol. Modell., 204, 79-84.

Manly, B. F. J., 2007: Randomization, Bootstrap and Monte Carlo Methods in Biology. Chapman \& Hall/CRC, 301 pp.

- L. L. McDonald, D. L. Thomas, T. L. McDonald, and W. P. Erickson, 2002: Resource Selection by Animals: Statistical Design and Analysis for Field Studies. 2nd ed. Kluwer Academic, $221 \mathrm{pp}$.

McClean, S. A., M. A. Rumble, R. M. King, and W. L. Baker, 1998: Evaluation of resource selection methods with different definitions of availability. J. Wildl. Manage., 62, 793-801.

Mielke, P. W., 1986: Non-metric statistical analyses: some metric alternatives. J. Statist. Plann. Inference, 13, 377-387. 
Earth Interactions • Volume 15 (2011) • Paper No. 19 • Page 11

Moreira, F., F. C. Rego, and P. G. Ferreira, 2001: Temporal (1958-1995) pattern of change in a cultural landscape of northwestern Portugal: Implications for fire occurrence. Landscape Ecol., 16, 557-567.

Nadeau, L. B., and P. Englefield, 2006: Fine-resolution mapping of wildfire fuel types for Canada: Fuzzy logic modeling for an Alberta pilot area. Environ. Monit. Assess., 120, 127-152.

Nielsen, S. E., C. J. Johnson, D. C. Heard, and M. S. Boyce, 2005: Can models of presence-absence be used to scale abundance? Two case studies considering extremes in life history. Ecography, 28, 197-208.

Nunes, M. C. S., M. J. Vasconcelos, J. M. C. Pereira, N. Dasgupta, and R. J. Alldredge, 2005: Land cover type and fire in Portugal: Do fires burn land cover selectively? Landscape Ecol., 20, $661-673$.

Pereira, J. M. C., and R. M. Itami, 1991: GIS-based habitat modelling using logistic multiple regression: A study of the Mt. Graham red squirrel. Photogramm. Eng. Remote Sens., 57, $1475-1486$.

Pezzatti, G. B., M. Conedera, and A. Kaltenbrunner, 2005: Die neue Waldbranddatenbank. Bündnerwald, 58, 37-39.

— S. Bajocco, D. Torriani, and M. Conedera, 2009: Selective burning of forest vegetation in Canton Ticino (southern Switzerland). Plant Biosyst., 143, 609-620.

Podur, J., and D. L. Martell, 2009: The influence of weather and fuel type on the fuel composition of the area burned by forest fires in Ontario, 1996-2006. Ecol. Appl., 19, 1246-1252.

Vasconcelos, M. J. P., S. Silva, M. Tomé, M. Alvim, and J. M. C. Pereira, 2001: Spatial prediction of fire ignition probabilities: Comparing logistic regression and neural networks. Photogramm. Eng. Remote Sens., 67, 73-81.

Earth Interactions is published jointly by the American Meteorological Society, the American Geophysical Union, and the Association of American Geographers. Permission to use figures, tables, and brief excerpts from this journal in scientific and educational works is hereby granted provided that the source is acknowledged. Any use of material in this journal that is determined to be "fair use" under Section 107 or that satisfies the conditions specified in Section 108 of the U.S. Copyright Law (17 USC, as revised by P.IL. 94553) does not require the publishers' permission. For permission for any other from of copying, contact one of the copublishing societies. 